\title{
Procedimentos de colheita dos frutos na qualidade fisiológica de sementes de Sapindus saponaria Mart
}

\author{
Sapindus saponaria seeds physiological quality resulting from \\ procedures for harvesting the fruits
}

\author{
Cibele Chalita Martins ${ }^{1 *}$; Claudemir Zucareli²; Rogério Andrade Coimbra ${ }^{3}$
}

\section{Resumo}

O estabelecimento do método e critérios de colheita adequados para cada espécie é necessário para a obtenção de sementes com máxima qualidade. O objetivo deste trabalho foi determinar o procedimento de colheita mais favorável à qualidade fisiológica de sementes de saboneteira. Cinco lotes de sementes foram colhidos, em diferentes anos, utilizando-se os seguintes critérios: fruto verde na planta; fruto amarelo na planta; fruto marrom na planta; fruto amarelo no chão e fruto marrom no chão. Após a extração, as sementes foram submetidas às seguintes determinações: teor de água, primeira contagem da germinação (14 dias), porcentagem de plântulas normais, anormais, sementes dormentes (duras), mortas (37 dias após a semeadura) e porcentagem de sementes viáveis. O delineamento experimental adotado foi o inteiramente ao acaso com 4 repetições de 50 sementes em esquema fatorial 5x5 (cinco lotes e cinco procedimentos de colheita). Os dados foram submetidos à análise de variância e as médias comparadas pelo teste de Tukey (p $<0,05)$. Os critérios adotados para a colheita afetaram as características físicas e fisiológicas das sementes de saboneteira. A colheita de frutos amarelos na planta resultou em sementes de saboneteira com maior qualidade fisiológica, mas para o êxito na germinação é necessário à superação de dormência.

Palavras-chave: Maturação, maturidade fisiológica, dormência, germinação, Sapindus saponaria Mart

\begin{abstract}
Using the more appropriate method when harvesting the fruits is the best way to get maximum Sapindus saponaria seeds quality. Seed lots of Sapindus saponaria were harvested according to the following procedures: (1) green fruits attached to the plant, (2) yellow fruits attached to the plant, (3) brown fruits attached to the plant, (4) yellow fruits lying down on the ground, and (5) brown fruits lying down on the ground. In each case the seeds were extracted from the fruits and submitted to the following analyses: water content, germination at the first count (14 days), normal and abnormal seedlings at final count, dormant (hard) seeds at final count, and viable seeds at final count (37 days). Harvesting the fruits from the mother plant while still yellow was found to result in the best quality seeds although breaking seed dormancy was verified to be of necessity.
\end{abstract}

Key words: Maturation, physiological maturity, dormancy, germination, Sapindus saponaria

\footnotetext{
1 Prof ${ }^{\mathrm{a}}$. Dra . do Centro Estadual de Educação Tecnológica do Estado de São Paulo "Paula Souza". Faculdade de Tecnologia em Silvicultura, FATEC. E-mail: cibele@fca.unesp.br

2 Prof. Dr. do Dept ${ }^{\circ}$ de Agronomia, Centro de Ciências Agrárias, Universidade Estadual de Londrina, UEL, Londrina, PR. E-mail: claudemircca@uel.br

3 Prof. Dr. da Universidade Federal de Mato Grosso, UFMT, Cuiabá, MT. E-mail: rcoimbra@ufmt.br

* Autor para correspondência
} 


\section{Introdução}

A saboneteira também conhecida como saboeiro, sabão-de-minas, sabonete e sabãode-macaco é uma planta pereniforme ou semidecídua, de ocorrência em florestas pluviais e semi-decíduas. A demanda por sementes e mudas desta espécie tem aumentado para o plantio como árvore ornamental devido ao baixo porte (até $8 \mathrm{~m}$ ), copa densa e globosa e, também, como planta medicinal, pois as raízes, frutos e casca apresentam substâncias adstringentes, antiespasmódicas, calmantes e antitussígenas (LORENZI, 2002).

A colheita de sementes com alta qualidade fisiológica é de reconhecida importância para a produção de mudas com rapidez e eficiência, maximizando outros investimentos do setor (NOGUEIRA; MEDEIROS, 2007). A colheita deve ser realizada quando as sementes atingem o ponto de maturidade fisiológica, pois neste estádio de desenvolvimento apresentam máxima porcentagem de germinação, vigor e matéria seca (MARCOS FILHO, 2005).

No campo, para a identificação do ponto de colheita de sementes de espécies florestais na maturidade fisiológica são empregados aspectos físicos dos frutos, tais como cor, tamanho, cheiro e abertura espontânea (NOGUEIRA; MEDEIROS, 2007; MARTINS et al., 2008b; MARTINELLISENEME; NAKAGAWA, 2008a). A mudança da cor do fruto, para muitas espécies, é um critério simples e confiável para avaliar a maturação e identificar o ponto de colheita no campo, contudo é necessário que o técnico tenha prática quanto a essa característica. A cor geralmente muda do verde para várias tonalidades de amarelo e marrom (NOGUEIRA; MEDEIROS, 2007).

Também a mudança da cor pode ser acompanhada do endurecimento do pericarpo e tegumento (NOGUEIRA; MEDEIROS, 2007; NAKAGAWA et al., 2007). Em algumas espécies, tem-se observado que há relação entre a coloração do tegumento e a sua permeabilidade à água (NAKAGAWA et al., 2007). A impermeabilização do tegumento à água ocorre durante a maturação das sementes, na fase de acúmulo de matéria seca e perda de água, ainda na planta mãe, e é máxima por ocasião da maturidade fisiológica (MURDOCH; ELLIS, 1993; DEMIR, 1997; MARCOS FILHO, 2005; NAKAGAWA et al., 2007).

As sementes de saboneteira apresentam dormência ocasionada pela impermeabilidade do tegumento à água, ou seja, sementes duras, e esta dormência pode ser superada mediante a escarificação das sementes com lixa número 60 por 30 segundos (FARIA; DAVIDE, 1991). A dormência torna-se um problema para os viveiristas, pois causa atraso e desuniformidade na germinação e na produção de mudas. Sementes de espécies florestais de lotes diferentes podem apresentar variações na intensidade de dormência e germinação devido a fatores genéticos e ambientais, pois são produzidos em diferentes anos, locais e podem ser coletadas em diferentes plantas matrizes (MARCOS FILHO, 2005; MARTINS; NAKAGAWA, 2008).

Portanto, são necessárias pesquisas enfocando metodologias de colheita de frutos de saboneteira, para que sejam obtidas sementes com máxima qualidade. Assim, o objetivo deste trabalho foi determinar procedimentos de colheita mais favoráveis à qualidade fisiológica de sementes de saboneteira.

\section{Material e Métodos}

Cinco lotes (L) de sementes de saboneteira foram colhidos em diferentes anos, de duas populações (p) distintas, localizadas no município de Botucatu, Estado de São Paulo: L1) ano de 2000 p1; L2) 2001 p1; L3) 2001 p2; L4) 2002 p1 e L5) 2003 p2.

Os frutos de cada lote foram colhidos na 
planta e no chão em um número mínimo de 15 plantas-mãe por população e foram transportados em embalagem de polietileno até o Laboratório de Análise de Sementes da UNESP - Campus de Botucatu, SP. Utilizando-se como referência uma carta de cores (GRAF, 1970), os frutos foram classificados em verdes (verde musgo-82), amarelos (ouro velho-5) e marrons (chocolate-7). Deste modo, foram avaliados cinco procedimentos de colheita (tratamentos): 1) fruto verde na planta; 2) fruto amarelo na planta; 3) fruto marrom na planta; 4) fruto amarelo no chão; 5) fruto marrom no chão. Para cada tratamento, as sementes foram extraídas dos frutos com auxílio de uma faca e imediatamente avaliadas quanto às seguintes características:

Teor de água - obtido por meio de quatro subamostras de 8 sementes a $105 \pm 3^{\circ} \mathrm{C}$ por $24 \mathrm{~h}$ (BRASIL, 2009) antes da instalação dos demais testes. Teste de germinação - conduzido com quatro subamostras de 50 sementes em rolo de papel na temperatura de $25^{\circ} \mathrm{C}$ e luz $(78 \mathrm{~mol} \mathrm{~s}-1$ $\mathrm{m}-2 / 8 \mathrm{~h}$ ) e contabilizando-se as porcentagens de plântulas normais, anormais, sementes dormentes (duras) e mortas (BRASIL, 2009) aos 37 dias após a semeadura. Primeira contagem da germinação - realizada mediante a contagem das plântulas normais presentes no teste de germinação (MARCOS-FILHO, 2005) aos 14 dias após a semeadura. Viabilidade - ao final do teste de germinação as sementes duras foram escarificadas com lixa por 30 segundos (FARIA; DAVIDE, 1991) e colocadas para germinar seguindo procedimento descrito no teste de germinação e, ao final de 37 dias, as plântulas normais foram somadas às anteriormente contabilizadas no teste germinação e o resultado foi apresentado em porcentagem de sementes viáveis.

A análise estatística foi realizada em esquema fatorial $5 \times 5$ (cinco lotes e cinco estratégias de colheita) em delineamento inteiramente casualizado com quatro repetições. Os dados foram submetidos a análise de variância e as médias comparadas pelo teste de Tukey $(\mathrm{P}<0,5)$.

\section{Resultados e Discussão}

Os frutos colhidosverdesnaplantaapresentaram sementes com os maiores teores de água $(52 \%$ em média), superiores aos apresentados pelos demais procedimentos de colheita ( $12 \%$ em média) (Tabela 1). O teor de água das sementes para os frutos colhidos amarelos ou marrons, na planta ou no chão não diferiram entre si, para a maioria dos lotes avaliados; exceção aos lotes 1 e 4 . Os frutos colhidos na planta dos lotes 1 e 4 apresentaram sementes com teores de água decrescentes com o avanço da maturação, pois frutos verdes, amarelos e marrons apresentaram valores médios de $46 \%, 14 \%$ e $10 \%$, respectivamente. Provavelmente, este decréscimo acentuado pode ser atribuído às condições meteorológicas de baixa umidade relativa do ar vigente por ocasião do final da maturação dos frutos de saboneteira nos anos de 2000 e 2002, quando os lotes 1 e 4 foram colhidos, o que deve ter favorecido e intensificado o processo de desidratação antes da dispersão (MARCOS FILHO, 2005).

Para o lote 1, verificou-se, no entanto, que frutos marrons colhidos no chão apresentaram um teor de água relativamente alto (28\%), inferior somente aos frutos verdes; esse fato foi causado pela absorção de água da chuva, que ocorreu na noite anterior à colheita. Os frutos do chão tiveram maior contato com a água acumulada no solo e, por mais tempo que os da árvore e, os frutos marrons hidrataram mais que os amarelos devido à baixa porcentagem de sementes duras; de $12 \%$ e $58 \%$, respectivamente. Assim, os lotes de frutos marrons colhidos no chão apresentaram maiores variações entre os lotes quanto ao teor de água das sementes do que os amarelos do chão ou da planta e marrons da planta, pois estavam mais susceptíveis às variações das condições ambientais de umidade. 


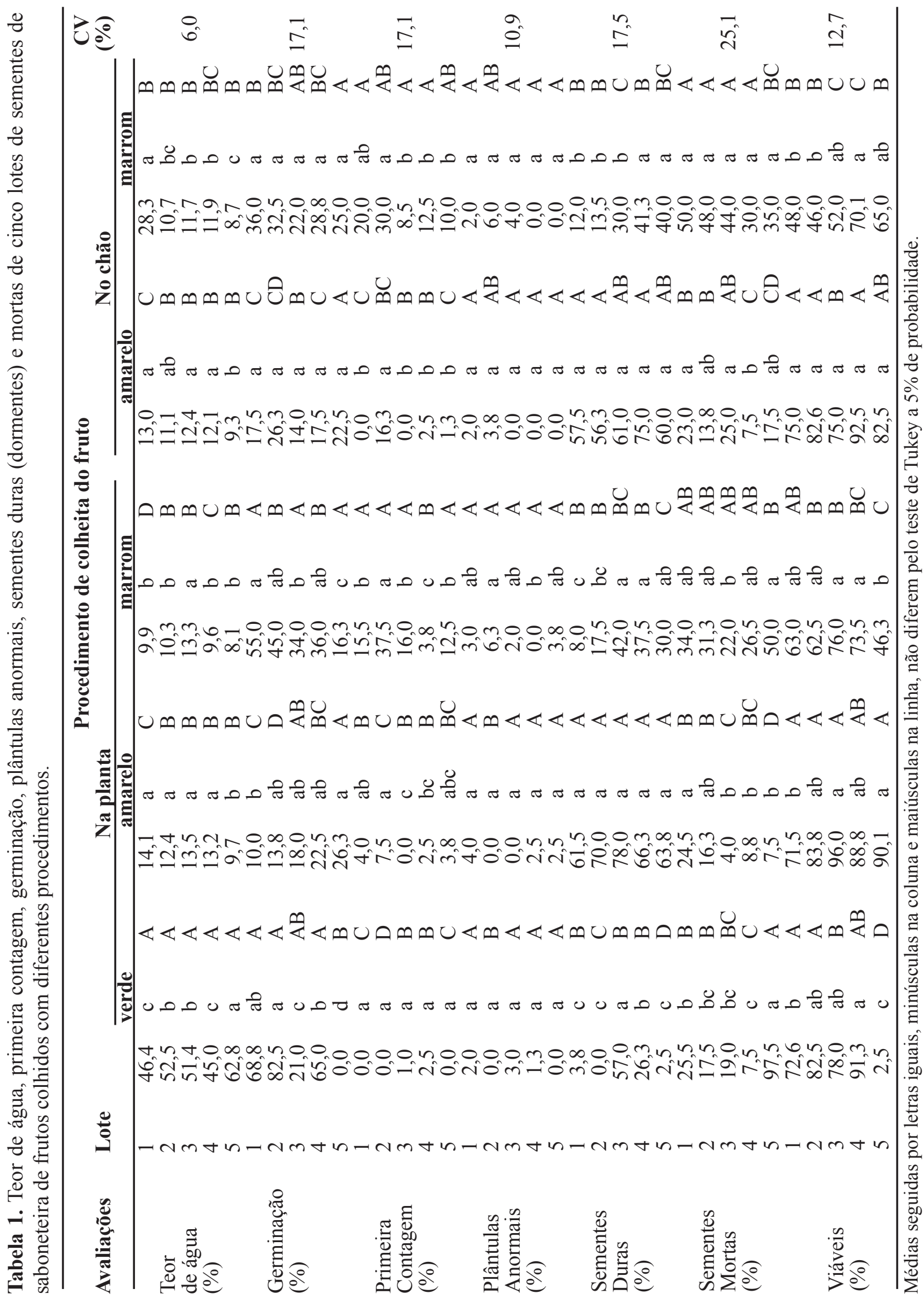


Os lotes de frutos colhidos verdes também apresentaram diferenças de maior amplitude no teor de água das sementes, pois embora os frutos tivessem a mesma cor e aparência externa, as sementes desses lotes apresentavam diferentes graus de maturação, pois além da diferença no teor de água das sementes verificou-se ampla variação da porcentagem de germinação $(0 \%$ e $83 \%)$, de sementes duras $(0 \%$ e $57 \%)$, mortas ( $8 \%$ e $98 \%)$ e viáveis $(3 \%$ e $91 \%)$ dependendo do lote avaliado. Essas variações da qualidade física e fisiológica das sementes de frutos verdes indicam que este procedimento de colheita não garante a obtenção de sementes de qualidade pois, embora alguns lotes, como 1 e 2 , tenham apresentado alta germinação e baixa porcentagem de sementes duras, e o lote 4 máxima viabilidade e mínima porcentagem de sementes mortas, que são características desejadas, houve inconsistência de resultados entre os lotes evidenciando a influência de ano e de populações.

Dentre os lotes de frutos colhidos verdes, o lote 5 apresentou as sementes mais imaturas, com as mais altas porcentagens de teor de água e de sementes mortas, 63\% e 98\%, respectivamente; aliados às mais baixas porcentagens de germinação $(0,0 \%)$, de sementes viáveis $(2,5 \%)$ e duras $(2,5 \%)$, (Tabela1). De modo oposto, o lote 3 apresentou as sementes mais maduras, pois a dureza tegumentar estava instalada, verificando-se $57 \%$ de sementes duras; valor relativamente elevado e superior ao apresentado pelos demais lotes. Por esse motivo, a porcentagem de germinação foi a segunda mais baixa, embora com valores intermediários de teores de água (51\%) e de sementes mortas (19\%). Para frutos colhidos verdes todos os lotes apresentaram valores similares de plântulas anormais e de vigor pelo teste da primeira contagem.

Ao analisar os efeitos dos procedimentos de colheita sobre a primeira contagem verifica-se que frutos colhidos marrons, na planta ou no chão possuem sementes com máxima velocidade de germinação, exceto para o lote 4 em sementes de frutos colhidos marrons na planta. Esses resultados foram favorecidos pelas baixas porcentagens de dormência das sementes de frutos marrons, pois a dormência atrasa o processo germinativo, constituindo uma estratégia de sobrevivência e perpetuação das espécies que possibilita a distribuição da germinação ao longo do tempo (MARCOS FILHO, 2005; NAKAGAWA et al., 2007; MARTINS; NAKAGAWA, 2008). A dormência devido à impermeabilidade do tegumento a água comumente se instala no final do processo de maturação das sementes e antes da desidratação (MARCOS FILHO, 2005; NAKAGAWA et al., 2007). Deste modo, verificou-se na (Tabela 1) que os frutos verdes também apresentaram as mais baixas porcentagens de sementes duras para todos os lotes avaliados, exceto para o lote 3. Assim, para os frutos colhidos verdes pode-se inferir que a baixa velocidade de germinação verificada no teste da primeira contagem, pode ser atribuído ao baixo vigor das sementes, relacionado a incompleta formação do fruto, e não à alta porcentagem de dormência.

A dormência, detectada pela porcentagem de sementes duras exerceu efeito sobre a velocidade de germinação e a porcentagem de germinação, e estes parâmetros variaram com o procedimento de colheita. Caso fosse avaliada a porcentagem de germinação isoladamente, a colheita de frutos verdes seria vantajosa, pois resultou em sementes com máxima germinação para quatro dos cinco lotes avaliados. No entanto, deve-se considerar que a dormência pode ser superada com eficiência antes da semeadura. $\mathrm{O}$ passar do tempo no armazenamento ou a escarificação mecânica das sementes podem ser estratégias utilizadas pelos viveiros de produção de mudas para a superação da dormência e a promoção da germinação (FARIA; DAVIDE, 1991; MARCOS FILHO, 2005). Portanto tornase, também, relevante identificar os procedimentos de colheita que possibilitem a obtenção de maiores porcentagens de sementes viáveis (vivas), ou seja, capazes de germinar após a superação da dormência 
e mínima porcentagem de sementes mortas.

Considerando-se a viabilidade e a porcentagem de sementes mortas na colheita de frutos marrons na planta e, principalmente, no chão foram os procedimentos de colheita mais prejudiciais à qualidade fisiológica das sementes para a quase totalidade dos lotes avaliados. Provavelmente as sementes de frutos desta cor já haviam ultrapassado o ponto de maturidade fisiológica, e o desempenho germinativo deveu-se à baixa taxa de sementes duras (Tabela 1).

De modo oposto, a colheita de frutos amarelos embora tenha apresentado porcentagem de germinação relativamente baixa para a maioria dos lotes, apresentou as maiores porcentagem de sementes viáveis. As sementes obtidas de frutos amarelos colhidos na planta apresentaram valores máximos de viabilidade ( $86 \%$ em média) em todos os lotes avaliados; e as sementes de frutos amarelos no chão apresentaram valores médios de $81 \%$, somente não apresentando máxima viabilidade para o lote 3 colhido no chão.

\section{Conclusões}

A colheita de frutos amarelos na planta resultou em sementes de saboneteira com maior viabilidade e qualidade fisiológica, mas para o êxito na germinação é necessário a superação de dormência

\section{Referências}

BRASIL. Ministério da Agricultura, Pecuária e Abastecimento. Secretaria de Defesa Agropecuária. Regras para análise de sementes. Brasília, 2009. 399 p.

DEMIR, I. Ocurrence of hardseededness in relation to seed development in okra (Abelmoshus esculentus (L.). Moench). Plant Varieties and Seeds, Cambridge, v. 10, n. 1, p. 7-13, 1997.

FARIA, J. M. R.; DAVIDE, A. C. Quebra de dormência em sementes de saboneteira (Sapindus saponaria L. Sapindaceae). Informativo ABRATES, Brasília, v. 1, n. 4, p. 82, 1991.

GRAF, A. B. Exotica horticultural color guide. In: GRAF,
A. B. (Ed.). Exotica 3; Pictorial cyclopedia of exotic plants. Rutherford, Roehrs, 1970. p. 37-38.

LORENZI, H. Árvores brasileiras: manual de identificação e cultivo de plantas arbóreas nativas do Brasil. Nova Odessa: Instituto Plantarum, 2002. 368 p.

MARCOS FILHO, J. Fisiologia de sementes de plantas cultivadas. Piracicaba: FEALQ, 2005. 495 p.

MARTINS, C. C.; BELISSÁRIO, L.; TOMAZ, C. A.; ZUCARELI, C. Condições climáticas, características do fruto e sistema de colheita na qualidade fisiológica de sementes de jacarandá. Revista Árvore, Viçosa, v. 32, n. 4, p. 627-632, 2008b.

MARTINS, C. C.; MARTINELLI-SENEME, A.; NAKAGAWA, J. Estágio de colheita e substrato para o teste de germinação de sementes de ipê (Tabebuia chrysotricha (Mart. ex DC.) Standl.). Revista Árvore, Viçosa, v. 32, n. 1, p. 27-32, 2008a.

MARTINS, C. C.; NAKAGAWA, J. Germinação de sementes de Stryphnodendron adstringens (Mart.) Coville de diferentes origens submetidas a tratamentos para superação de dormência. Revista Árvore, Viçosa, v. 32, n. 6, p. 1059-1067, 2008.

MURDOCH, A. J.; ELLIS, R. H. Longevity, viability and dormancy. In: FENNER, M. (Ed.). Seeds: the ecology of regeneration in plant communities. Wallingford: $\mathrm{CAB}$ International, 1993. p. 193-229.

NAKAGAWA, J.; CAVARIANI, C.; MARTINS, C. C.; COIMBRA, R. A. Intensidade de dormência durante a maturação de sementes de mucuna-preta. Revista Brasileira de Sementes, Brasília, v. 29, n. 1, p. 165-170, 2007.

NOGUEIRA, A. C.; MEDEIROS, A. C. S. Coleta de sementes florestais nativas. Colombo: Embrapa Florestas, 2007. 11 p. (Embrapa Florestas. Circular Técnica, 144). 